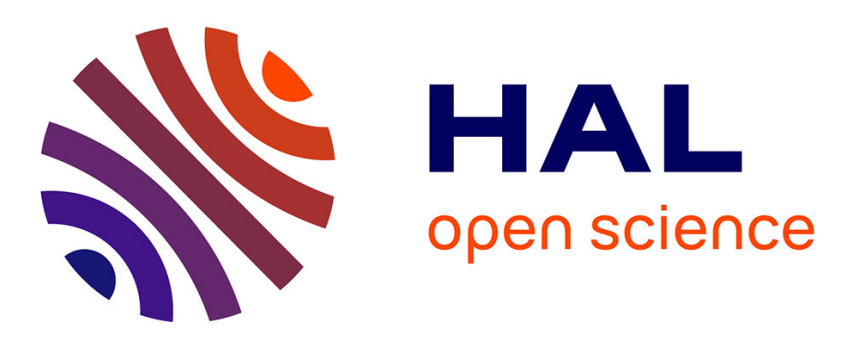

\title{
The behavior of cancellous bone from quasi-static to dynamic strain rates with emphasis on the intermediate regime
}

Marianne Prot, Trevor John Cloete, Dominique Saletti, Sébastien Laporte

\section{- To cite this version:}

Marianne Prot, Trevor John Cloete, Dominique Saletti, Sébastien Laporte. The behavior of cancellous bone from quasi-static to dynamic strain rates with emphasis on the intermediate regime. Journal of Biomechanics, 2016, 49 (7), pp.1050-1057. 10.1016/j.jbiomech.2016.02.021Get . hal-02468211

\author{
HAL Id: hal-02468211 \\ https://hal.science/hal-02468211
}

Submitted on 5 Feb 2020

HAL is a multi-disciplinary open access archive for the deposit and dissemination of scientific research documents, whether they are published or not. The documents may come from teaching and research institutions in France or abroad, or from public or private research centers.
L'archive ouverte pluridisciplinaire HAL, est destinée au dépôt et à la diffusion de documents scientifiques de niveau recherche, publiés ou non, émanant des établissements d'enseignement et de recherche français ou étrangers, des laboratoires publics ou privés. 


\title{
The behavior of cancellous bone from quasi-static to dynamic strain rates with emphasis on the intermediate regime
}

\author{
M. Prot ${ }^{\text {a,* }}$, T.J. Cloete ${ }^{\mathrm{b}}$, D. Saletti ${ }^{\mathrm{a}, \mathrm{c}}$, S. Laporte ${ }^{\mathrm{a}}$ \\ ${ }^{a}$ LBM/Institut de Biomécanique Humaine Georges Charpak, Arts et Métiers ParisTech, 151 Boulevard de l'Hôpital, 75013 Paris, France \\ ${ }^{\mathrm{b}}$ Blast Impact and Survivability Research Unit (BISRU), Department of Mechanical Engineering, University of Cape Town (UCT), Private bag X3, Rondebosch \\ 7701, South Africa \\ ${ }^{\mathrm{c}}$ Univ. GrenobleAlpes, 3SR, F-38000 Grenoble, France
}

\begin{abstract}
A B S T R A C T
Previous studies, conducted using quasi-static and dynamic compression tests, have shown that the mechanical strength of cancellous bone is strain rate dependent. However, these studies have not included the intermediate strain rate (ISR) regime (1/s to $100 / \mathrm{s})$, which is important since it is representative of the loading rates at which non-fatal injuries typically occur. In this study, 127 bovine bone specimens were compressed in 3 regimes spanning 8 distinct strain rates, from $0.001 / \mathrm{s}$ to $600 / \mathrm{s}$, using three different devices: a conventional quasi-static testing machine, a wedge-bar (WB) apparatus and a conventional split Hopkinson pressure bar (SHPB) implemented with a cone-in-tube (CiT) striker and a tandem momentum trap. Due to the large sample size, a new robust automated algorithm was developed with which the material properties, such as the apparent Young's modulus and the yield and ultimate values of stress and strain, were identified for each individual specimen. A statistical summary of the data is presented. Finally, this study demonstrates that results obtained at intermediate strain rates are essential for a fuller understanding of cancellous bone behavior by providing new data describing the transition between the quasi-static and dynamic regimes.
\end{abstract}

Keywords:

Cancellous bone

Intermediate strain rate

Interrupted tests

Quasi-static

Dynamic

Hopkinson bar

\section{Introduction}

An improved understanding of cancellous bone fracture, along with detailed knowledge of cortical bone behavior, is necessary to advance human musculoskeletal modelling. Bone is composed of an inner core structure of cancellous bone, which hosts the bone marrow while supporting the shape of and transferring forces to the load bearing outer shell of dense cortical bone. For this reason the mechanical behavior of cancellous bone needs to be well understood and modelled. Several cancellous bone modelling approaches have been investigated, such as lattice homogenization (Goda et al., 2014), function based modelling (Pasko et al., 2011), random media (Padilla et al., 2003), finite element analysis (Hambli, 2013) and skeleton based models (Van Lenthe et al., 2006). Human bone is subjected to dynamic loadings on a daily basis with intensities that range from falls of elderly individuals (low level) to vehicle accidents (high level). Whichever model is used, its fidelity suffers from a lack of representative data. Literature studies have primarily focused on quasi-static compression loadings (up to 0.1/s, equivalent to a brisk run (Burr and Allen, 2013)), while more recently some researchers have developed dynamic compression tests $\left(10^{2}-10^{3} / \mathrm{s}\right.$ (Shim et al., 2005; Pilcher et al., 2010; Johnson, 2010)). While some authors have reported studies on the mechanical response of cancellous bone at intermediate strain rates (from 1/s (Halgrin, 2009) to 10/s (Carter and Hayes, 1977; Linde et al., 1991)), there is a general lack of data for this range, which is mainly due to experimental difficulties experienced with traditional devices used in experimental mechanics, i.e. deformation velocities are too low for split Hopkinson bar set-ups using conventional strikers while the initial accelerations are too high for standard hydraulic testing machines with a cut-off frequency response in the order of $1 \mathrm{kHz}$. While some studies have reported trabeculae behavior to be unaffected by the strain rate (Szabó et al., 2011), the general consensus is that cancellous bone behavior is strain rate dependent (Guedes et al., 2006), and can vary with anatomic location, among other factors (Morgan and Keaveny, 2001; Hulme et al., 2007). Therefore, this rate dependence should be investigated at strain rates that are representative of typical accidents, such as falling (Burr and Allen, 
2013) or vehicle collisions (Hiermaier, 2007), in order to improve model predictions and contribute to the development of enhanced protection solutions. However, natural variations between specimens from different sources make comparisons difficult and there appear to be no published studies in which specimens from a common source were tested at strain rates from quasi-static, through the intermediate and up to the dynamic regime. Hence, the aim of the present study is to develop a robust method to characterize a large randomized set of cancellous bone specimens under compression loading in 3 different regimes equivalent at 8 distinct strain rates from $0.001 / \mathrm{s}$ to $600 / \mathrm{s}$.

\section{Materials and methods}

\subsection{Samples}

In total, 127 cylindrical cancellous bone specimens (length: $7.5 \mathrm{~mm}$; diameter $10.5 \mathrm{~mm}$ ) were extracted from 6 different femoral bones of 4 years old cattle. A slow cutting speed was used in order to avoid thermal degradation of the specimen and mechanical damage to the peripheral trabeculae. The anatomical positions and orientations were recorded during sampling (i.e., femoral head/great trochanter; sagittal, transversal, and frontal). The non-defatted bovine specimens were stored frozen in a saline solution (Linde and Sørensen, 1993) and thawed for $24 \mathrm{~h}$ at $+5{ }^{\circ} \mathrm{C}$ before being brought up to room temperature prior to testing (Mitton et al., 1997). These tests were conducted within the animal welfare regulations and guidelines of South Africa.

\subsection{Experimental technique}

Compression experiments at various strain rates $(\dot{\varepsilon})$ were conducted using three different devices: A standard universal testing machine for low strain rate and two custom-made devices to compress cancellous bone material at elevated strain rates.

\subsubsection{Universal testing machine}

A Zwick 1484 universal testing machine was used for quasi-static compression $\left(10^{-3} / \mathrm{s}<\dot{\varepsilon}<10^{-1} / \mathrm{s}\right)$ of cancellous bone specimens up to the first collapses of trabeculae. Specimens were preloaded in order to minimize potential parallelism defects.

\subsubsection{Wedge bar apparatus}

A wedge bar (WB) apparatus (Cloete et al., 2014), illustrated in Fig. 1, was adapted to test cancellous bone.

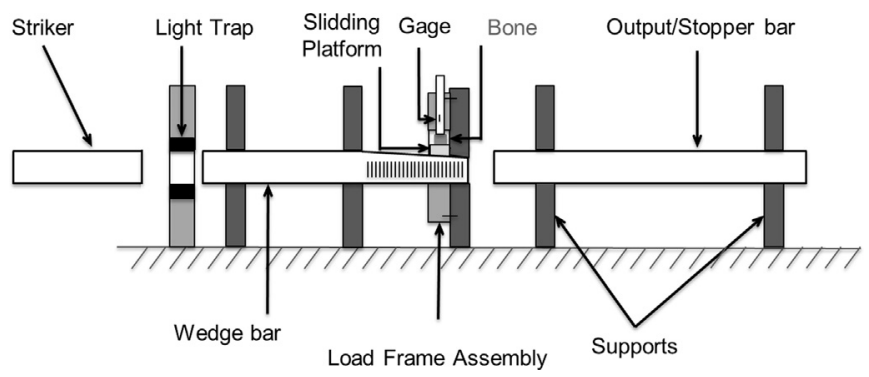

Fig. 1. Wedge bar apparatus system.

The wedge-bar layout consists of a load frame assembly and three $20 \mathrm{~mm}$ diameter steel bars: the striker, wedge bar and stopper bar, which are nominally identical except for a shallow wedge machined into the wedge bar. The wedge bar can move through the load frame assembly, which consists of a load frame, backing plate, load cell and sliding anvil, which has a lower surface machined to match the wedge. The length of wedge bars and ratios used vary from $1500 \mathrm{~mm}$ and $500 \mathrm{~mm}$ for $1 / \mathrm{s}$ to $500 \mathrm{~mm}$ and $200 \mathrm{~mm}$ for $10 / \mathrm{s}$, but in all cases the maximum anvil displacement is only $1 \mathrm{~mm}$, which is sufficient to fracture the specimen Further details of the wedge-bar technique are given by Cloete et al. (2014).

During testing, the striker is fired from a gas gun and comes to rest through colinear elastic impact upon the wedge-bar, which rapidly attains the desired test velocity. The wedge-bar motion, which is captured using a reflective object sensor, causes the sliding anvil to compress a small cylindrical specimen against the load cell, which captures the load history. The specimen deformation is inferred from the wedge bar motion, which is arrested through impact with the carefully positioned stopper bar to enable specimen recovery at a well-defined final strain (between $5 \%$ and $10 \%$, i.e., after the elastic range but before densification of the broken trabeculae).

The wedge-bar is suited to the ISR regime. The compact load frame assembly, with no fluid components, rapidly attains equilibrium. The shallow wedge angle generates large forces with a large speed reduction, which ensures a near constant deformation rate because the wedge-bar kinetic energy is far greater than required to deform the specimen.

\subsubsection{Modified Split Hopkinson Pressure Bar}

In this study, a standard Split Hopkinson Pressure Bar (SHPB) apparatus was implemented with a cone-in-tube (CiT) striker and a tandem momentum trap, as shown in Fig. 2.

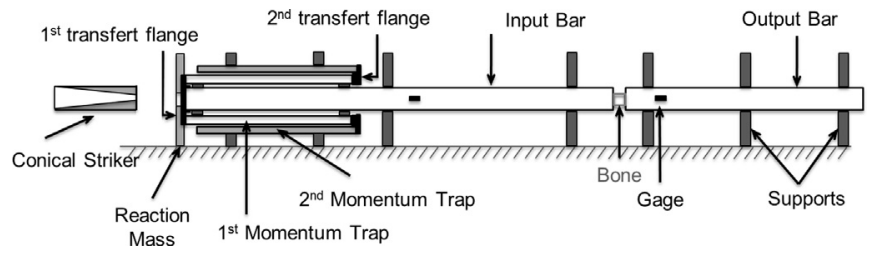

Fig. 2. SHPB set-up implemented with a CiT striker and a tandem momentum trap.

In a conventional SHPB test, a uniform striker, typically launched using a gas gun, impacts upon the input bar, causing a compressive stress wave to propagate along the bar and deform the specimen. Since the specimen has a lower strength and impedance than the two bars, it deforms while supporting only a portion of the load, which is transmitted into the output bar, while the remaining portion reflects back into the input bar as tensile stress wave. By capturing and analysing the three stress waves using the principles of elastic wave propagation, the strength of the specimen can be determined under dynamic loading conditions.

The use of the CiT striker allows for the constant strain rate compression of a bone specimen to a point just after the ultimate stress, after which the tandem momentum trap allows for whole specimen recovery without any subsequent reloading.

The CiT striker produces a trapezoidal stress wave with a steeply rising central slope that is tailored to compensate for the anticipated increase in the specimen response during a test and thus ensures a near constant strain rate compression. This, in turn, allows the impact velocity to be reduced, resulting in a strain rate in the upper IRS regime.

The tandem momentum trap consists of two nested co-axial aluminum tubes that are impedance matched to the input bar and placed in mutual contact using transfer flanges, as shown in Fig. 2. The function of the outer tube is to ensure that the inner tube remains in contact with the input bar by capturing the stress waves transferred through the inner tube during the striker impact. In this way, the inner tube is correctly positioned to capture the reflected pulse in the input bar after the specimen has been deformed and thus prevent further loading of the specimen.

For this study, a $20 \mathrm{~mm}$ diameter by $3.3 \mathrm{~m}$ long aluminum input bar was used with a $20 \mathrm{~mm}$ diameter by $2 \mathrm{~m}$ long magnesium output bar to increase the intensity of the output signal. The CiT striker and the momentum trap tubes were also made from aluminum of a similar grade to that of the input bar. Further details of the CiT striker and tandem momentum trap techniques are given by Cloete et al. (2014) and Prot and Cloete (2016), respectively.

\subsection{Specimen distribution}

Specimens were divided into three strain rate regimes: quasi-static (QS), intermediate (ISR) and dynamic ( $D$ ), spanning 8 different strain rates (Table 1). Each specimen was carefully inspected before being incorporated into one of the sets. The specimens with observed architectural abnormalities, such as a machining error or the presence of cartilage, were removed from the study. Furthermore, if the recorded test signal had too much noise effects, the specimen was also discarded from the study. Specimens with similar anatomical locations and orientations were evenly divided between the specimen sets.

Table 1

Specimen repartition.

\begin{tabular}{|c|c|c|c|c|c|c|c|c|}
\hline \multirow{2}{*}{$\begin{array}{l}\text { Regime } \\
\text { Strain rate }\end{array}$} & \multicolumn{3}{|c|}{ Quasi-static } & \multicolumn{3}{|c|}{ Intermediate } & \multicolumn{2}{|c|}{ Dynamic } \\
\hline & $0.001 / \mathrm{s}$ & $0.01 / \mathrm{s}$ & $0.1 / \mathrm{s}$ & $1 / \mathrm{s}$ & $10 / \mathrm{s}$ & $100 / \mathrm{s}$ & $400 / \mathrm{s}$ & $600 / \mathrm{s}$ \\
\hline Apparatus & Zwick & Zwick & Zwick & Wedge & Wedge & SHPB & SHPB & SHPB \\
\hline \multirow{2}{*}{$\begin{array}{l}\text { Number of } \\
\text { specimens }\end{array}$} & 10 & 9 & 24 & 22 & 14 & 18 & 20 & 10 \\
\hline & & \multicolumn{2}{|l|}{43} & \multicolumn{3}{|c|}{54} & \multicolumn{2}{|c|}{30} \\
\hline
\end{tabular}




\subsection{Mechanical properties identification}

An automated robust data processing algorithm was developed (Prot et al. $2015 b)$ to extract the mechanical properties from the experimental load-deflection curves, such as the apparent Young's Modulus, $E_{\mathrm{app}}$, the yield stress and strain, $\varepsilon_{\mathrm{y}}$ and $\sigma_{\mathrm{y}}$ and the ultimate stress and strain, $\varepsilon_{\mathrm{u}}$ and $\sigma_{\mathrm{u}}$ respectively. The algorithm is based on logistic risk curves (Ricketts and Head, 1999), and uses 5 parameters, as described in the equations given below: two horizontal tangents (named $\sigma_{1}$ for the asymptotic minimum stress, $\sigma_{2}$ for the asymptotic maximum stress), two slopes ( $E_{1}$ and $\left.E_{2}\right)$ and the strain value at the inflection point $\left(\varepsilon_{\text {infl }}\right)$.

$\sigma(\varepsilon)=\sigma_{1}+\frac{\sigma_{2}}{1+f(\varepsilon) g(\varepsilon)+(1-f(\varepsilon)) h(\varepsilon)}$

with:

$C=\frac{2 E_{1} E_{2}}{\left|E_{1}+E_{2}\right|} f(\varepsilon)=\frac{1}{1+e^{-C\left(\varepsilon-\varepsilon_{\text {inf }}\right)}} g(\varepsilon)=e^{E_{1}\left(\varepsilon-\varepsilon_{\text {inf }}\right)} h(\varepsilon)=e^{E_{2}\left(\varepsilon-\varepsilon_{\text {inf }}\right)}$

These 5 parameters were identified using a robust non-linear least square method. The apparent Young's modulus, $E_{\text {app, }}$ was identified as the slope at the inflexion point. The point of zero strain was obtained from the intersection of this slope and the zero stress axes: $\varepsilon_{0}$. The ultimate point, $\left(\varepsilon_{\mathrm{u}}\right.$ and $\left.\sigma_{\mathrm{u}}\right)$, was systematically defined as the maximum stress value, previously named $\sigma_{2}$, and the corresponding strain. The end of the linear domain has been defined by minimizing the distance between each point of the model curve and the slope at the inflection point. A normal distance greater than half of the average of the distances is set as an exclusion criterion. A bootstrap method (Efron and Tibshirani, 1994) was implemented in order to estimate the evaluation errors on each parameter due to experimental noise.

\subsection{Data analysis}

A Kruskal-Wallis test was carried out to investigate the relative influence of the bone provenance, the anatomic direction, the location in the femur and the strain rate. This test was used because, despite the large sample size, the number of specimen was still below the optimum number necessary for a quantitative ANOVA analysis. A p-value of 0.05 was chosen as the upper threshold of significance. All statistical tests described here (McDonald, 2009), were performed using XLSTAT ${ }^{\circ}$. Finally, a Mann-Whitney statistical test (non-parametric hypothesis test) was used to appraise the suitability of the three strain rate groupings by studying the interaction between a given strain rate and the three neighboring sets.

\section{Results}

\subsection{Mechanical parameters}

The mechanical parameters evaluation algorithm was successfully applied to the three different regimes (Fig. 3). The algorithm successfully captured the toe region, even when moderate noise levels were present (Fig. 3(b)).

A non-exhaustive list of the resulting data is summarized in Table 2. The maximum estimation error for $E_{\text {app }}$ was $10.3 \mathrm{MPa}$ (1.8\%) at a strain rate of $10 / \mathrm{s}$, due to the load cell noise, leading to a maximum error estimate for $\varepsilon_{0}$ of $0.06 \%$.

\subsection{Location and strain rate sensitivity}

The sensitivity results for the ultimate stress are illustrated in Fig. 4.

The data confirms that bone provenance has no influence on the ultimate stress value (Fig. 4(a)). Furthermore, the mechanical parameters are consistent between the six bones. Indeed, the minimum $p$-value of the Kruskal-Wallis test of 0.16 , obtained for $\varepsilon_{\mathrm{y}}$, is higher than the significant level of 0.05 : there is no significant difference between the samples obtained from different bones. In other words, this clearly indicates that it is not relevant to consider here the influence of bone provenance on the mechanical response.

The data presented in Fig. 4(b) suggest that the direction orthogonal to transversal plane of the bone has a higher ultimate strength. However, the minimum observed Kruskal-Wallis test a

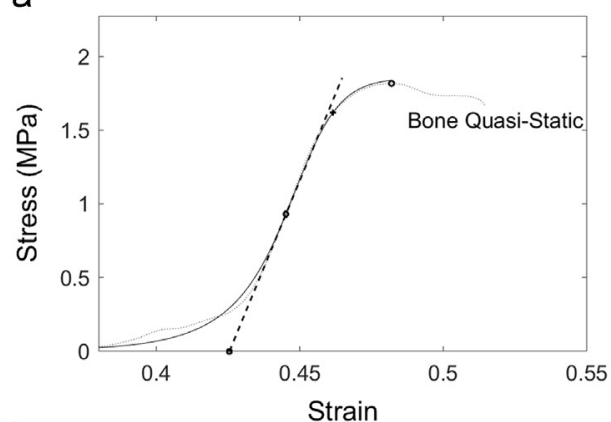

b
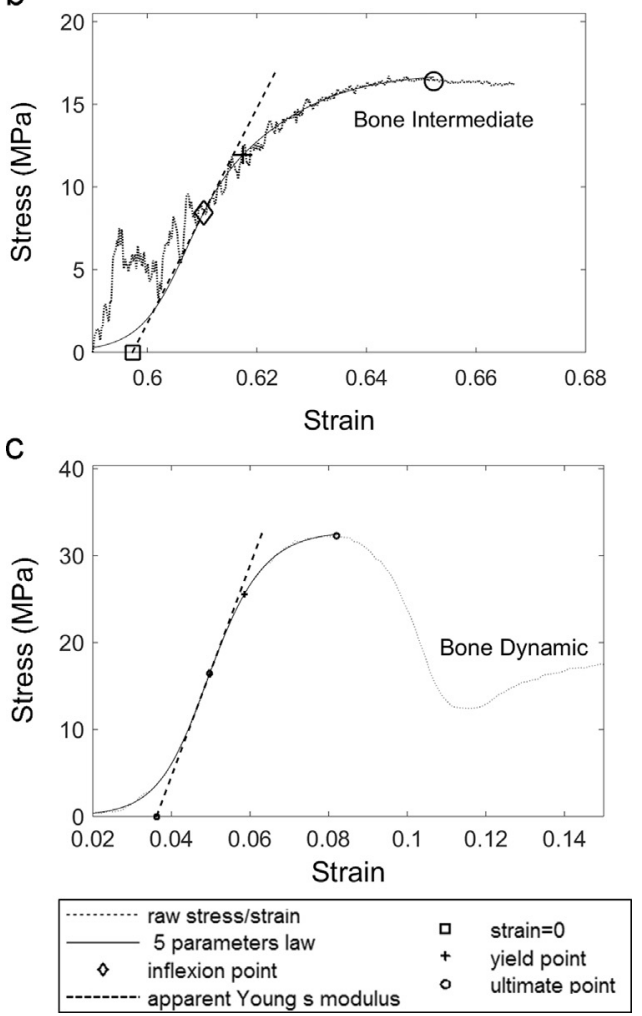

Fig. 3. Mechanical parameters evaluation in three strain rate regimes. (a) Quasistatic (example at $0.1 / \mathrm{s}$ ), (b) intermediate (example at $10 / \mathrm{s}$ ), and (c) dynamic (example at 600/s).

$p$-value of 0.15 implies that there is not a significant difference between the anatomic sets (frontal, sagittal, and transversal).

By contrast, the Kruskal-Wallis statistical test does indicate that there is a significant difference in the $E_{\mathrm{app}}, \sigma_{\mathrm{y}}$ and $\sigma_{\mathrm{u}}$ values based on the anatomical locations from which the specimens were harvested. This is a reasonable result since specimens from the femoral head, which experiences a greater load in daily life, can be expected to have greater strength (Fig. 4(c)).

Finally the data confirms that mechanical behavior of cancellous bovine bone is strain rate dependent (Fig. 4(d)). In particular, the combined effect of strain rate and anatomical location (femoral head versus great trochanter) has the greatest influence on the mechanical properties.

\subsection{Strain rate grouping}

Historically, the various strain rate regions (QS, ISR, and D) have been defined based on the machines required to test in those regimes and not on the inherent behavior of the materials being tested. Hence, as mentioned in Section 2.5, a Mann-Whitney statistical test was used to appraise the suitability of the three strain 
Table 2

Mechanical parameters and statistical description.

\begin{tabular}{|c|c|c|c|c|c|c|c|c|c|c|c|c|c|c|c|c|c|c|c|c|c|c|c|c|}
\hline \multirow{2}{*}{$\begin{array}{l}\text { Mech. param. } \\
\text { Strain rate (/s) }\end{array}$} & \multicolumn{8}{|l|}{$\varepsilon_{\mathrm{y}}(\%)$} & \multicolumn{8}{|c|}{$\sigma_{\mathrm{y}}(\mathrm{MPa})$} & \multicolumn{8}{|c|}{$E_{\text {app }}(\mathrm{MPa})$} \\
\hline & 0.001 & 0.01 & 0.1 & 1 & 10 & 100 & 400 & 600 & 0.001 & 0.01 & 0.1 & 1 & 10 & 100 & 400 & 600 & 0.001 & 0.01 & 0.1 & 1 & 10 & 100 & 400 & 600 \\
\hline Mean & 2.1 & 2.4 & 2.6 & 3.8 & 2.3 & 2.1 & 2.4 & 2.6 & 6.5 & 8 & 7.3 & 8.7 & 11.3 & 11.2 & 10.1 & 12.7 & 322.9 & 365 & 299.8 & 285.8 & 585.7 & 629.3 & 471.2 & 573.3 \\
\hline Standard dev. & 0.3 & 0.3 & 0.4 & 2 & 0.8 & 0.3 & 0.4 & 0.7 & 4.9 & 5.7 & 5.2 & 5.9 & 6.4 & 7.5 & 6.3 & 6.3 & 216.5 & 250.3 & 192 & 171.5 & 386.2 & 479.6 & 333.6 & 313.7 \\
\hline Minimum & 1.6 & 1.7 & 2 & 1.2 & 0.9 & 1.6 & 1.7 & 1.5 & 2.2 & 1.5 & 1.6 & 2.8 & 6.7 & 2.2 & 1.5 & 3.4 & 118.1 & 64.9 & 47.4 & 77.2 & 251.3 & 80.6 & 67.8 & 119.2 \\
\hline 1st Quartile & 2 & 2.3 & 2.3 & 2.3 & 1.8 & 1.9 & 2.2 & 2.2 & 3.1 & 3.5 & 3.4 & 4.2 & 7.9 & 5.8 & 5.2 & 8.6 & 176.4 & 134.3 & 158.4 & 174.9 & 362.6 & 269.5 & 237.5 & 450.7 \\
\hline Median & 2.1 & 2.3 & 2.4 & 3.2 & 2.2 & 2 & 2.3 & 2.5 & 3.9 & 6 & 5.2 & 6.2 & 9.3 & 9.9 & 6.9 & 13.2 & 207.6 & 276.5 & 239.9 & 243.2 & 423.9 & 540.4 & 327.8 & 569.3 \\
\hline 3rd Quartile & 2.2 & 2.5 & 2.8 & 5.6 & 2.8 & 2.2 & 2.7 & 2.7 & 9.5 & 13.4 & 10 & 13.3 & 11.4 & 13.3 & 16 & 15.3 & 498.5 & 613.1 & 413.6 & 357.3 & 569 & 708.4 & 706 & 670.1 \\
\hline Maximum & 2.5 & 2.7 & 3.6 & 7.8 & 3.7 & 2.9 & 3.4 & 4.1 & 15.1 & 16.2 & 19.2 & 23 & 29 & 29 & 22.9 & 25.6 & 676.1 & 685.5 & 727.8 & 684.1 & 1401 & 1806 & 1233 & 1213 \\
\hline Mech. param. & \multicolumn{8}{|l|}{$\varepsilon_{\mathrm{u}}(\%)$} & \multicolumn{8}{|c|}{$\sigma_{\mathrm{u}}(\mathrm{MPa})$} & & & & & & & & \\
\hline Strain rate $(/ \mathrm{s})$ & 0.001 & 0.01 & 0.1 & 1 & 10 & 100 & 400 & 600 & 0.001 & 0.01 & 0.1 & 1 & 10 & 100 & 400 & 600 & & & & & & & & \\
\hline Mean & 4.8 & 5.4 & 5.5 & 11 & 4.7 & 3.2 & 4.6 & 4.3 & 8.3 & 10.2 & 9.4 & 12 & 14.6 & 13.4 & 12.5 & 15.3 & & & & & & & & \\
\hline Standard dev. & 1 & 0.9 & 0.7 & 4.8 & 1.6 & 0.8 & 1 & 1.1 & 6.1 & 7.3 & 6.7 & 7.8 & 8.4 & 8.6 & 7.8 & 8.2 & & & & & & & & \\
\hline Minimum & 3.5 & 4 & 4.2 & 2.9 & 1.9 & 2.3 & 2.3 & 2.3 & 2.6 & 1.7 & 1.8 & 4.1 & 8.6 & 2.5 & 2 & 3.6 & & & & & & & & \\
\hline 1st Quartile & 3.8 & 5.1 & 5 & 6.9 & 3.7 & 2.7 & 3.9 & 3.7 & 3.9 & 4.4 & 4.6 & 5.4 & 9.9 & 6.9 & 6.4 & 9.8 & & & & & & & & \\
\hline Median & 4.8 & 5.6 & 5.5 & 11.6 & 4.4 & 3.2 & 4.6 & 4.2 & 5.2 & 7.8 & 7 & 9 & 11.5 & 12.4 & 9.1 & 15.7 & & & & & & & & \\
\hline 3rd Quartile & 5.7 & 5.8 & 5.7 & 15.3 & 6.2 & 3.4 & 5.4 & 4.7 & 12.2 & 17.3 & 13.3 & 18.4 & 15.3 & 16.5 & 19.1 & 19.3 & & & & & & & & \\
\hline Maximum & 6.1 & 6.8 & 7 & 18.8 & 7.3 & 5.9 & 5.8 & 6.3 & 18.8 & 20.7 & 25.2 & 30.2 & 36.9 & 33.3 & 29.6 & 32.3 & & & & & & & & \\
\hline
\end{tabular}

Yield point, $\left(\varepsilon_{\mathrm{y}}, \sigma_{\mathrm{y}}\right)$, ultimate point, $\left(\varepsilon_{\mathrm{u}}, \sigma_{\mathrm{u}}\right)$, and apparent Young's modulus $E_{\mathrm{app}}$. 
a

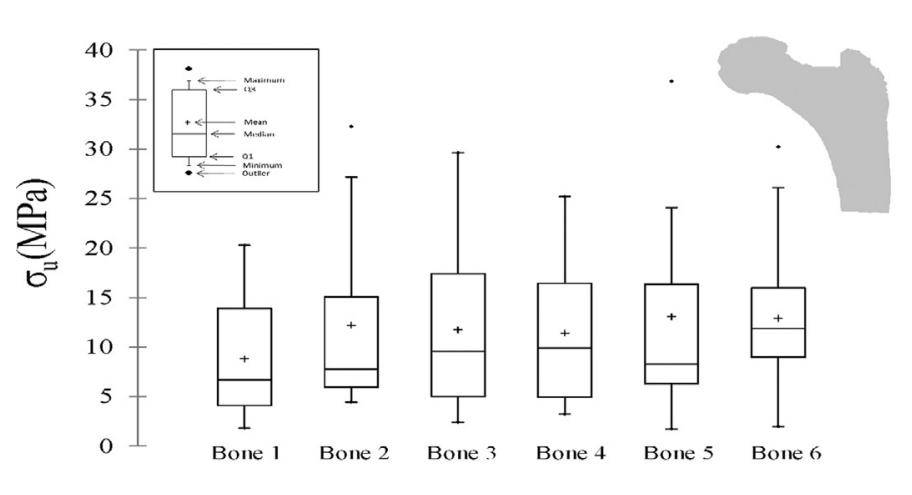

b

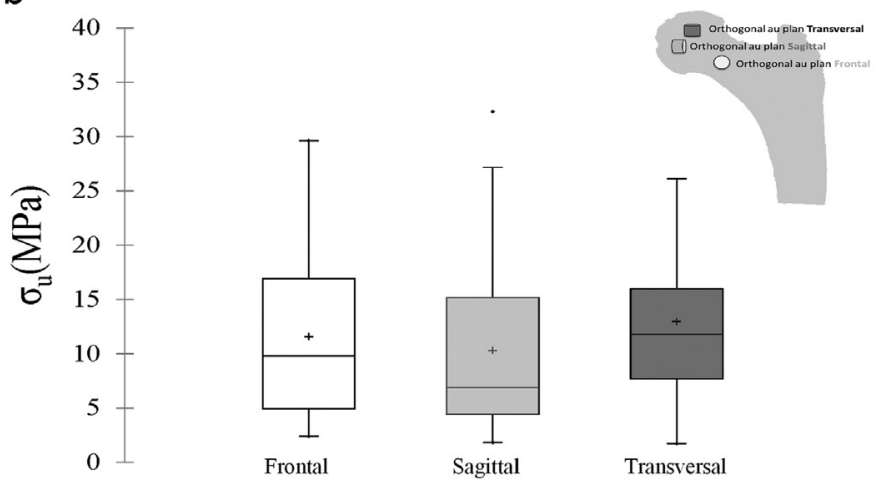

d

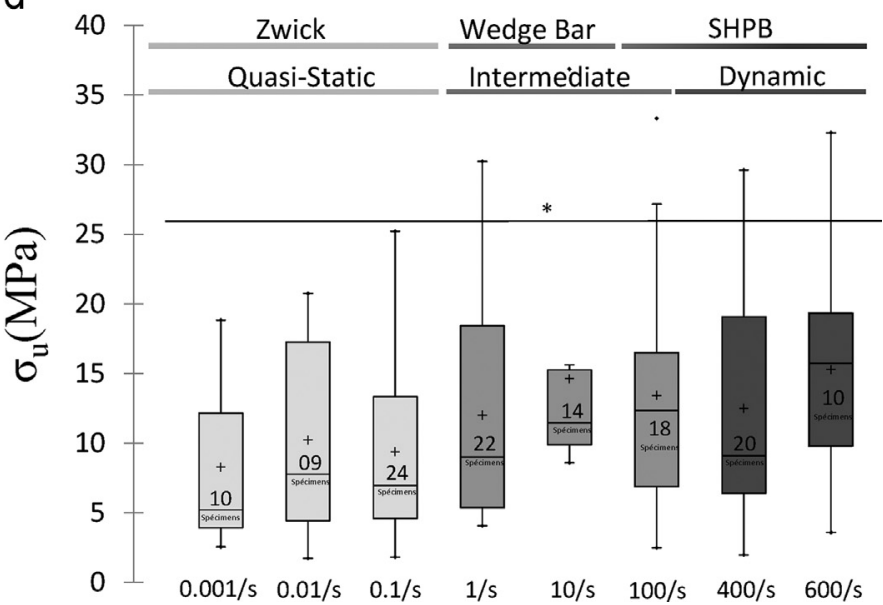

C
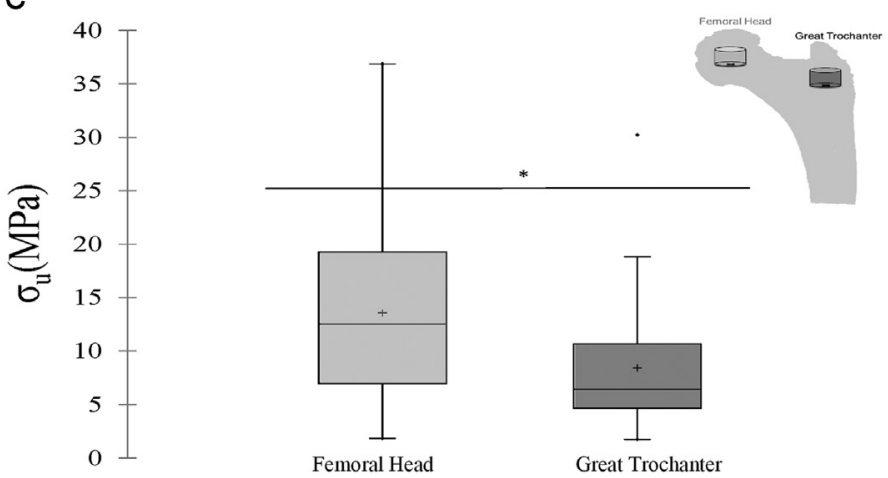

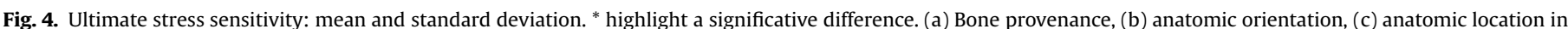
the femur, and (d) strain rate (/s).

Table 3

Mann-Whitney statistical test results on $E_{\mathrm{app}}$ and $\varepsilon_{\mathrm{u}}$.

(a) Apparent Young's modulus $\mathrm{E}_{\text {app }}$

\begin{tabular}{|c|c|c|c|c|c|c|c|c|}
\hline$E_{a p p}$ & 0.001 & 0.01 & 0.1 & 1 & 10 & 100 & 400 & 600 \\
\hline 0.001 & $100 \%$ & $78 \%$ & $92 \%$ & $98 \%$ & & & & \\
\hline 0.01 & $78 \%$ & $100 \%$ & $59 \%$ & $50 \%$ & $23 \%$ & & & \\
\hline 0.1 & $92 \%$ & $59 \%$ & $100 \%$ & $98 \%$ & $1 \%$ & $1 \%$ & & \\
\hline 1 & $98 \%$ & $50 \%$ & $98 \%$ & $100 \%$ & $1 \%$ & $1 \%$ & $5 \%$ & \\
\hline 10 & & $23 \%$ & $1 \%$ & $1 \%$ & $100 \%$ & $92 \%$ & $18 \%$ & $55 \%$ \\
\hline 100 & & & $1 \%$ & $1 \%$ & $92 \%$ & $100 \%$ & $40 \%$ & $94 \%$ \\
\hline 400 & & & & $5 \%$ & $18 \%$ & $40 \%$ & $100 \%$ & $39 \%$ \\
\hline 600 & & & & & $55 \%$ & $94 \%$ & $39 \%$ & $100 \%$ \\
\hline
\end{tabular}

(b) Ultimate Strain $\varepsilon_{u}$

\begin{tabular}{|c|c|c|c|c|c|c|c|c|}
\hline$\varepsilon_{\mathrm{u}}$ & 0.001 & 0.01 & 0.1 & 1 & 10 & 100 & 400 & 600 \\
\hline 0.001 & $100 \%$ & $24 \%$ & $15 \%$ & $0 \%$ & & & & \\
\hline 0.01 & $24 \%$ & $100 \%$ & $92 \%$ & $0 \%$ & $42 \%$ & & & \\
\hline 0.1 & $15 \%$ & $92 \%$ & $100 \%$ & $0 \%$ & $22 \%$ & $0 \%$ & & \\
\hline 1 & $0 \%$ & $0 \%$ & $0 \%$ & $100 \%$ & $0 \%$ & $0 \%$ & $0 \%$ & \\
\hline 10 & & $42 \%$ & $22 \%$ & $0 \%$ & $100 \%$ & $0 \%$ & $65 \%$ & $60 \%$ \\
\hline 100 & & & $0 \%$ & $0 \%$ & $0 \%$ & $100 \%$ & $0 \%$ & $1 \%$ \\
\hline 400 & & & & $0 \%$ & $65 \%$ & $0 \%$ & $100 \%$ & $50 \%$ \\
\hline 600 & & & & & $60 \%$ & $1 \%$ & $50 \%$ & $100 \%$ \\
\hline
\end{tabular}

The probability that there is no significant difference between two strain rates is expressed as a percentage. Darkened: risk less than $5 \%$. Strain rate groups are illustrated in bold framed. 
rate groupings to cancellous bone, the results of which are presented as a non-exhaustive summary in Table 3. The apparent Young's modulus results support the division of the mechanical response into three regimes by confirming the consistency of behavior in the quasi-static and dynamic regimes while highlighting the abrupt transition that occurs in the intermediate regime. The ultimate stress $\left(\sigma_{\mathrm{u}}\right)$ results do not provide any additional information, but are compatible with the strain rate grouping. A similar result was obtained for the yield stress $\left(\sigma_{\mathrm{y}}\right)$ but is not reported here for the sake of brevity.

\section{Discussion}

The data (Table 2) concurs with published quasi-static data focused on bovine cancellous femoral bone characterization (Kefalas and Eftaxiopoulos, 2012) while being slightly higher than bovine costal bone (Halgrin, 2009). The results were also compared to that for human tibial cancellous bone which has been investigated up to the intermediate regime (Carter and Hayes, 1977; Linde et al., 1991). The present study shows a similar degree of variation. Furthermore, the stress values are comparable to the literature dedicated to human cervical cancellous bone (Shim et al., 2005) compression from the upper intermediate regime (100/s) up to the dynamic regime, but are slightly higher than values for dynamic human tibial characterization (Teja et al., 2013). Data on tibial bovine bone (Pilcher et al., 2010) shows a similar range of ultimate stress values while the apparent Young's modulus has a higher range than in this study.

This study highlighted the importance of doing compression at a constant strain rate (i.e., use of the CiT striker). For the SHPB tests, dynamic specimen equilibrium was confirmed through near identical specimen interfaces force histories, which also showed that the specimens were not reloaded. The decrease in the apparent Young's modulus with an increasing strain rate observed by Prot et al. (2015a) and in Chocron et al. (2012) was not observed here, which is attributed to the constant strain rate maintained during testing. For example, Fig. 5(a) shows the strain rate history as a function of strain for two typical wedge-bar tests in the intermediate regime while Fig. 5(b) shows the strain rate and stress histories for a typical SHBP test as previously described. In all cases, the desired near constant strain rate was achieved for the majority of the test duration, with a slight decrease evident at a strain rate of $1 / \mathrm{s}$. For the SHPB tests the near constant strain rate persists until the first ruptures of the trabeculae, after which the sudden decrease in the specimen stiffness causes the strain rate to rise, as shown in Fig. 5(b).

This study confirms that mechanical behavior of cancellous bovine bone is sensitive to strain rate, as illustrated in Fig. 4(d), with a rate dependence of approximately $3.8 \mathrm{kPa} /$ decade determined from the 8 strain rates considered. Furthermore, the statistical results confirm that the rate effect is significant, although some caution is still advised due to the presence of the outliers (Fig. 4). In this regard, the reduced variation in the data at a strain rate of $10 / \mathrm{s}$ may simply be due to the relatively small set of successful tests in that range.

Table 2 shows that, in general, the results are consistent, although some scatter is observed. The scatter in the value of the mechanical parameters is known to be affected by several factors, such as the bone provenance (Morgan and Keaveny, 2001; Hulme et al., 2007), the method of testing and the method of material parameter identification. The apparent Young's modulus was found higher ( $20 \%$ for a $60 \%$ difference in strain rate) than that previously reported by the first two authors (Prot et al., 2015a) for a similar range of ultimate stress and strain values. This emphasizes the need to conduct test series with large specimen sets so as a

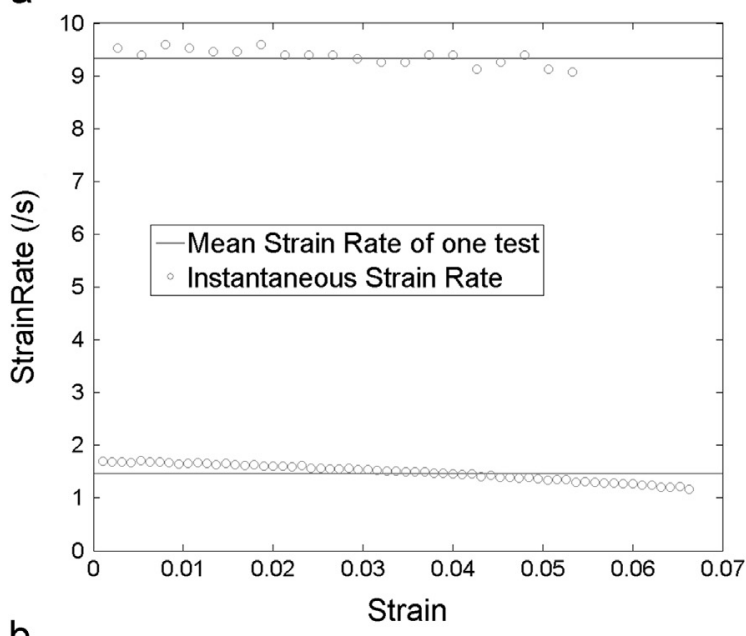

b

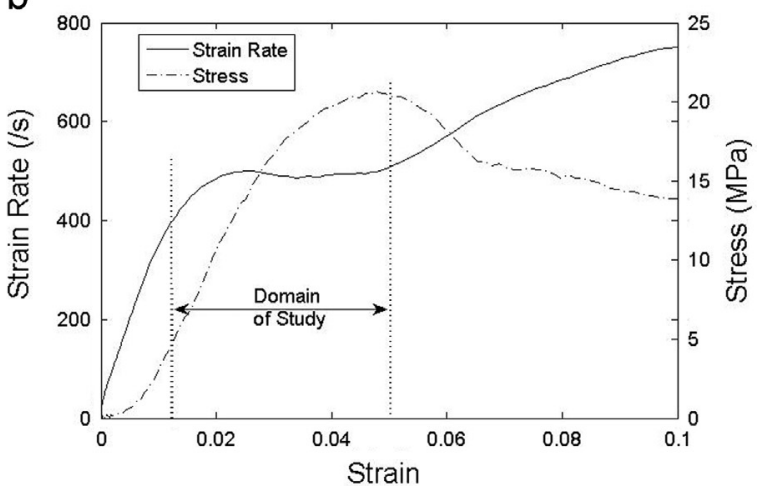

Fig. 5. Examination of constant strain rate hypothesis. (a) Wedge Bar system (b) SHPB with momentum trap and conical striker.

to minimize this variability. Nevertheless, one anomalous result is evident in the data: Table 2 shows an increase in the yield and ultimate strains for a loading rate of $1 / \mathrm{s}$ while the three other parameters $\left(E_{\mathrm{app}}, \sigma_{\mathrm{y}}\right.$, and $\sigma_{\mathrm{u}}$ ) are consistent with the rest of the data set. It is not a standard practice to use the strain as a trustworthy parameter: the literature indicates that they did not bring correlation, with architectural parameters for example (Teo et al., 2006). However, the results of this study show generally consistent yield and ultimate strain values in all the strain rate regimes. The experimental results at $1 / \mathrm{s}$ were re-analyzed in great detail and no systematic error in the raw data or subsequent processing was found. For example, the slight decrease in the strain rate with the strain Fig. 5(a), is also evident at $10 /$ s, and is therefore unlikely to be responsible for anomalous result. Hence, the reason for this phenomenon is unclear at this time and is a topic for ongoing research.

The division of the data into three regimes observed in Table 3 (b) is evident: two distinct regimes (quasi-static and dynamic) for which the behavior can be clearly identified and a transient regime (intermediate) in which a different behavior takes place. The transient intermediate response cannot be an artifact of an experimental technique as different testing devices were used in the intermediate strain rate range and give consistent results. Likewise, the difference between observed apparent Young's modulus values at $1 / \mathrm{s}$ and $10 / \mathrm{s}$, highlighted in Table 3(a), is not an artifact to the testing technique as a same set up was used at both strain rates. Recent investigations also showed a rapid transition in the strain rate sensitive behavior of bovine cortical bone in the intermediate regime (Cloete et al., 2014). Furthermore, it is interesting to note that the literature highlights an increase in the brittleness of cortical bone (also expressed as a decrease in the 
fracture toughness), with an increase in the strain rate (McElhaney, 1966; Adharapurapu et al., 2006; Kulin et al., 2011; Bekker et al., 2015), while the present results indicate an increase of the cancellous bone strength and ductility. This suggests that damage tolerance is increased by the presence of cancellous bone, which is consistent with its ubiquity at repetitive impact sites, such as joints at ends of long bones.

Table 3 also shows that, the results obtained at a strain rate of $10 / \mathrm{s}$ do not present a sample set difference with those at $0.01 / \mathrm{s}$ in regard to both $E_{\text {app }}$ and $\sigma_{\mathrm{u}}$. Similarly, for the ultimate strain, no significant difference was observed between results obtained at $0.1 / \mathrm{s}, 400 / \mathrm{s}$ and $600 / \mathrm{s}$. The difference highlighted with its immediate closest strain rates $1 / \mathrm{s}$ and $100 / \mathrm{s}$ in regards with $\sigma_{\mathrm{u}}$ confirms that these statistical results need to be carefully considered. The reduced variation in the data at a strain rate of $10 / \mathrm{s}$ highlighted previously may accentuate the observed phenomenon while the Mann-Whitney test clearly states strain rates groupings with a transition at intermediate regime.

The sensitivity to the location in the femur (great trochanter versus femoral head) confirms the dependency of cancellous bone behavior to the architecture (Geraldes and Phillips, 2010). Furthermore, cancellous bone specimens sampled from a same bone, same anatomical position (direction and position in the femur) and machined from adjacent portions of bone presented a slight behavior difference (example illustrated in Fig. 6). Indeed, a comparable yield and ultimate strains are observed but a variability of the ultimate stress appeared. This stress variability might be induced by the difference in trabeculae organization within the specimen. Indeed, the heterogeneous and porous architecture of cancellous bone has been further linked to the low strain rate behavior in order to predict the fracture location (Tassani and Matsopoulos, 2014) and the global mechanical response (Zhou et al., 2014) and recently at high strain rate (Prot et al., 2015a). This overview of the sensitivity to the architecture needs to be completed by a 3D characterization of the spongy structure.

In conclusion, this study provides mechanical parameters that have been robustly determined across a large range of different strain rates, including novel data in the intermediate regime. The preliminary results indicate that a distinct transition occurs in the strain rate sensitivity of cancellous bovine bone in the ISR regime between the strain rates of 1 and 10/s. Ongoing work focused on the pre-test architectural characterization of the specimens will investigate the role of the porous organization in the fracture process. Similar work on the postfracture examination of the recovered test specimens is aimed at investigating the strain rate

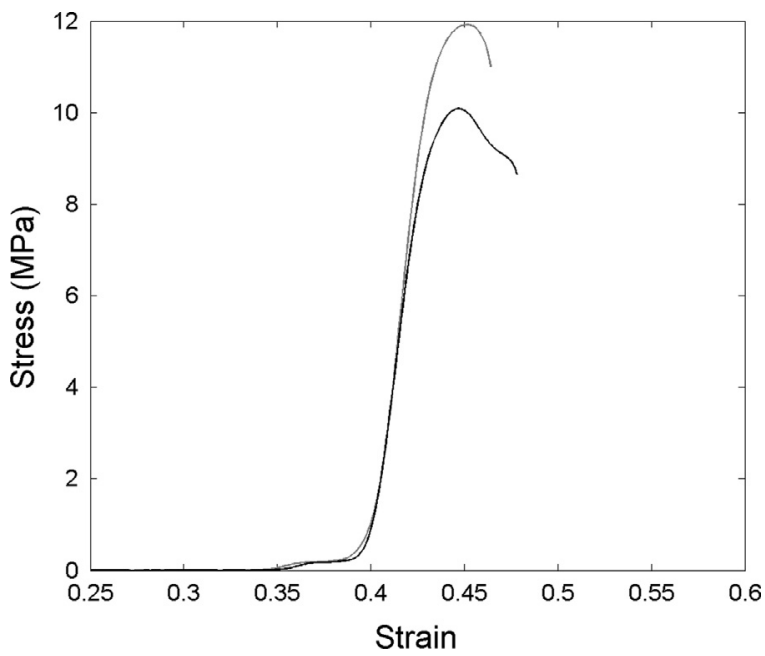

Fig. 6. Stress-strain evolutions of two closely sampled specimens. effects on the location of bone fracture initiation. Furthermore, future work using confined tests, especially in the intermediate regime, is expected to overcome some of the limitations of this study by providing more realistic boundary conditions similar to that applied in situ by adjacent cortical and cancellous bone, which contains and restrains the flow of bone marrow.

\section{Conflict of interest statement}

We wish to confirm that there are no known conflicts of interest associated with this publication and there has been no significant financial support for this work that could have influenced its outcome.

\section{Acknowledgment}

The authors wish to thank Sacks Butcheries for supplying the bovine femurs, Mr. C. Harris (UCT) for the machining of the specimens, Ms. P. Park Ross (UCT) for her assistance with the Zwick Machine and the UCT Research Committee for the financial support to conduct this work.

\section{References}

Adharapurapu, R.R., Jiang, F., Vecchio, K.S., 2006. Dynamic fracture of bovine bone Mater. Sci. Eng. C 26 (8), 1325-1332.

Bekker, A., Cloete, T.J., Chinsamy-Turan, A., Nurick, G.N., Kok, S., 2015. Constant strain rate compression of bovine cortical bone on the split-Hopkinson pressure bar. Mater. Sci. Eng. C 46, 443-449.

Burr, D.B., Allen, M.R., 2013. Basic and Applied Bone Biology. Academic Press.

Carter, D.R., Hayes, W.C., 1977. The compressive behavior of bone as a two-phase porous structure. J. Bone Jt. Surg. Am. 59, 954-962.

Chocron, S., Nicolella, D., Nicholls, A.E., Bredbenner, T., Havill, L., 2012. Dynamic testing of old and young baboon cortical bone with numerical validation. In: EPJ Web of Conferences, vol.26, p. 03004. (EDP Sciences).

Cloete, T.J., Paul, G., Ismail, E.B., 2014. Hopkinson bar techniques for the intermediate strain rate testing of bovine cortical bone. Philos. Trans. R. Soc. A Math. Phys. Eng. Sci. 372 (2015), 20130210.

Efron, B., Tibshirani, R.J., 1994. An Introduction to the Bootstrap, vol. 57. CRC press.

Geraldes, D.M., Phillips, A.T.M., 2010. A novel 3D strain-adaptive continuum orthotropic bone remodelling algorithm: prediction of bone architecture in the femur. In: Proceedings of the 6th World Congress of Biomechanics (WCB 2010), August 1-6, 2010, Springer, Berlin, Heidelberg, Singapore, pp. 772-775.

Goda, I., Assidi, M., Ganghoffer, J.F., 2014. A 3D elastic micropolar model of vertebral trabecular bone from lattice homogenization of the bone microstructure. Biomech. Model. Mechanobiol. 13 (1), 53-83.

Guedes, R.M., Simoes, J.A., Morais, J.L., 2006. Viscoelastic behavior and failure of bovine cancellous bone under constant strain rate. J. Biomech. 39 (1), 49-60.

Halgrin, J., 2009. Influence des paramètres architecturaux sur le comportement mécanique de l'os trabéculaire (Ph.D. thesis). Université Lille Nord-de-France. Available from: $\langle$ http://tel.archives-ouvertes.fr/tel-00494612/ $\rangle$.

Hambli, R., 2013. Micro-CT finite element model and experimental validation of trabecular bone damage and fracture. Bone 56 (2), 363-374.

Hiermaier, S., 2007. Structures under Crash and Impact: Continuum Mechanics, Discretization and Experimental Characterization. Springer Science \& Business Media.

Hulme, P.A., Boyd, S.K., Ferguson, S.J., 2007. Regional variation in vertebral bone morphology and its contribution to vertebral fracture strength. Bone 41 (6) 946-957.

Johnson, T.P.M., 2010. On the Rate-dependent Constitutive Response of Cortical and Trabecular Bone (Ph.D. thesis). Massachusetts Institute of Technology. Available from 〈http://hdl.handle.net/1721.1/62325

Kefalas, V., Eftaxiopoulos, D.A., 2012. Experimental study of cancellous bone under large strains and a constitutive probabilistic model. J. Mech. Behav. Biomed. Mater. 6, 41-52.

Kulin, R.M., Jiang, F., Vecchio, K.S., 2011. Effects of age and loading rate on equine cortical bone failure. J. Mech. Behav. Biomed. Mater. 4 (1), 57-75.

Linde, F., Nørgaard, P., Hvid, I., Odgaard, A., Sballe, K., 1991. Mechanical properties of trabecular bone. Dependency on strain rate. J. Biomech., 803-809.

Linde, F., Sørensen, H., 1993. The effect of different storage methods on the mechanical properties of trabecular bone. J. Biomech., 1249-1252.

McDonald, J.H., 2009. Handbook of Biological Statistics.. Sparky House Publishing, Baltimore, MD. 
McElhaney, J.H., 1966. Dynamic response of bone and muscle tissue. J. Appl. Physiol. $21(4), 1231-1236$

Mitton, D., Rumelhart, C., Hans, D., Meunier, P.J., 1997. The effects of density and test conditions on measured compression and shear strength of cancellous bone from the lumbar vertebrae of ewes. Med. Eng. Phys., 464-474.

Morgan, E.F., Keaveny, T.M., 2001. Dependence of yield strain of human trabecular bone on anatomic site. J. Biomech., 569-577.

Padilla, F., Peyrin, F., Laugier, P., 2003. Prediction of backscatter coefficient in trabecular bones using a numerical model of three-dimensional microstructure. J. Acoust. Soc. Am. 113 (2), 1122-1129.

Pasko, A., Fryazinov, O., Vilbrandt, T., Fayolle, P.A., Adzhiev, V., 2011. Procedura function-based modelling of volumetric microstructures. Graph. Models 73 (5) 165-181.

Pilcher, A., Wang, X., Kaltz, Z., Garrison, J.G., Niebur, G.L., Mason, J., Chen, W., 2010. High strain rate testing of bovine trabecular bone. J. Biomech. Eng. 132 (8), 081012.

Prot, M., Saletti, D., Pattofatto, S., Bousson, V., Laporte, S., 2015a. Links between mechanical behavior of cancellous bone and its microstructural properties under dynamic loading. J. Biomech. 48, 498-503.

Prot, M., Cloete,T.J., Saletti, D., Laporte, S., 2015b. A robust method to identify cancellous bone behavior: from the quasi-static to intermediate and dynamic strain rates. In: Proceedings of the 25th Congress of the International Society of Biomechanics. Glasgow, UK.

Prot, M., Cloete, T.J., 2016. Design of a tandem momentum trap adapted for compressive split Hopkinson pressure bar: application to dynamic recovery of cancellous bone. J. Dyn. Behav. Mater.
Ricketts, J.H., Head, G.A., 1999. A five-parameter logistic equation for investigating asymmetry of curvature in baroreflex studies. Am. J. Physiol. 277 (2), R441-R454.

Shim, V.P.W., Yang, L.M., Liu, J.F., Lee, V.S., 2005. Characterisation of the dynamic compressive mechanical properties of cancellous bone from the human cervical spine. Int. J. Impact Eng. 32 (1), 525-540.

Szabó, M.E., Taylor, M., Thurner, P.J., 2011. Mechanical properties of single bovine trabeculae are unaffected by strain rate. J. Biomech. 44 (5), 962-967.

Tassani, S., Matsopoulos, G.K., 2014. The micro-structure of bone trabecular fracture: an inter-site study. Bone 60, 78-86.

Teja, C.K., Chawla, A., Mukherjee, S., 2013. Determining the strain rate dependence of cortical and cancellous bones of human tibia using a split Hopkinson pressure bar. Int. J. Crashworthiness 18 (1), 11-18.

Teo, J., Si-Hoe, K.M., Keh, J.E.L., Teoh, S.H., 2006. Relationship between CT-intensity, micro-architecture and mechanical properties of porcine vertebral cancellous bone. Clin. Biomech. 21 (3), 235-244.

Van Lenthe, G.H., Stauber, M., Müller, R., 2006. Specimen-specific beam models for fast and accurate prediction of human trabecular bone mechanical properties. Bone 39 (6), 1182-1189.

Zhou, B., Sherry Liu, X., Wang, J., Lucas Lu, X., Fields, A.J., Edward Guo, X., 2014 Dependence of mechanical properties of trabecular bone on plate-rod microstructure determined by individual trabecula segmentation (ITS). J. Biomech. 47 (3), 702-708. 